\title{
Sustainability education and a new master's degree, the master of sustainability science: the Graduate Program in Sustainability Science (GPSS) at the University of Tokyo
}

\author{
Motoharu Onuki · Takashi Mino
}

Received: 8 December 2008/Accepted: 29 January 2009/Published online: 27 March 2009

(C) Integrated Research System for Sustainability Science and Springer 2009

\begin{abstract}
The University of Tokyo started its Graduate Program in Sustainability Science (GPSS), offering a master of sustainability science degree, in 2007. The GPSS curriculum consists of: (1) knowledge and concept oriented courses, which cover sustainability-related subjects from a holistic viewpoint; (2) experiential learning and skills oriented practical courses, which offer practical exercises to acquire the skills and sensibility required of future leaders; and (3) the Master's thesis, for which students are encouraged to address complex sustainability problems through a transdisciplinary approach. Sustainability science is not a discipline that can be defined simply by the subjects it deals with, but is an academic field characterized by core principles that include holistic thinking, transdisciplinarity, and respect for diversity. The GPSS has been designed so that students may gain the capacity to understand and practice these principles. The present paper describes how the GPSS has defined sustainability education and designed its curriculum accordingly.
\end{abstract}

Keywords Sustainability education ·

Sustainability science $\cdot$ Diversity $\cdot$ Transdisciplinarity

M. Onuki ( $\square)$

Graduate Program in Sustainability Science (GPSS), Division of Environmental Studies, Graduate School of Frontier Sciences, The University of Tokyo, 5-1-5, Kashiwanoha, Kashiwa City, Chiba 277-8563, Japan e-mail: onuki@k.u-tokyo.ac.jp

\section{T. Mino}

Department of Socio-Cultural Environmental Studies, Division of Environmental Studies,

Graduate School of Frontier Sciences, The University of Tokyo,

5-1-5, Kashiwanoha, Kashiwa City, Chiba 277-8563, Japan

\section{Introduction}

In October 2007, the University of Tokyo started a new international master's program, the Graduate Program in Sustainability Science (GPSS), as an interdepartmental program of the five departments in the Division of Environmental Studies, Graduate School of Frontier Sciences (GSFS). The GPSS is also an educational activity of the Integrated Research System for Sustainability Science (IR3S), a nationwide research-education network founded in Japan to establish sustainability science as a new transdisciplinary academic field. The IR3S has five participating universities: the University of Tokyo, Kyoto University, Osaka University, Hokkaido University, and Ibaraki University. The Division of Environmental Studies and the IR3S have been collaborating in the development of the GPSS since its inception.

Those who have completed the GPSS are awarded a master of sustainability science degree. The present paper describes how the GPSS has defined and designed sustainability education at the postgraduate level.

\section{Objectives of the GPSS}

Sustainability science has been described by Kates et al. (2001) and Clark (2007) as “improving society's capacity to use the earth in ways that simultaneously meet the needs of a much larger but stabilizing human population, sustain the life support systems of the planet, and substantially reduce hunger and poverty." The IR3S recognizes sustainability science as an academic field that points the way to understanding the diverse issues associated with sustainability in a holistic manner and to propose visions and methods toward the development of a sustainable society (Komiyama and Takeuchi 2006). 
Table 1 Course list of the Graduate Program in Sustainability Science (GPSS)

\begin{tabular}{|c|c|c|}
\hline Course title & Description & Credits \\
\hline \multicolumn{3}{|l|}{ Knowledge and concept oriented courses } \\
\hline $\begin{array}{l}\text { Sustainability perspectives in environmental } \\
\text { issues* }\end{array}$ & Core; Environmental Management Program & 2 \\
\hline Environmental Economics* & Core; Environmental Management Program & 2 \\
\hline $\begin{array}{l}\text { Business administration for environmental } \\
\text { technology* }\end{array}$ & Core; Environmental Management Program & 2 \\
\hline Business and finance for sustainable development* & Core; Environmental Management Program & 2 \\
\hline Natural Environmental Studies for Sustainability* & Core; Department of Natural Environmental Studies & 2 \\
\hline Innovation and sustainability* & Core; GPSS original & 2 \\
\hline Urban sustainability in relation to the water sector* & $\begin{array}{l}\text { Core; Department of Socio-Cultural Environmental } \\
\text { Studies }\end{array}$ & 2 \\
\hline Strategies for global sustainability* & Core; TIGS & 2 \\
\hline Environmental sustainability* & Core; TIGS & 2 \\
\hline Frontier of sustainability Science* & Core; IR3S & 2 \\
\hline Bio-environmental studies II & Elective & 2 \\
\hline Marine resources and environment & Elective & 2 \\
\hline $\begin{array}{l}\text { Mineral resources development and environmental } \\
\text { protection }\end{array}$ & Elective & 2 \\
\hline Socio-environmental systems & Elective & 2 \\
\hline Design of environmentally harmonizing systems & Elective & 2 \\
\hline Marine environment modeling & Elective & 2 \\
\hline Residential environment & Elective & 2 \\
\hline Coastal environment infrastructure studies & Elective & 2 \\
\hline Structural safety of the built environment & Elective & 2 \\
\hline Advanced wind engineering & Elective & 2 \\
\hline $\begin{array}{l}\text { Water and wastewater treatment for material } \\
\text { recycling }\end{array}$ & Elective & 2 \\
\hline Development model & Elective & 2 \\
\hline Sustainability education & Elective & 2 \\
\hline \multicolumn{3}{|l|}{ Experiential learning and skills oriented practical courses } \\
\hline Case study course on sustainability science* & GPSS original & 2 \\
\hline $\begin{array}{l}\text { Practical course on systems thinking and consensus } \\
\text { building* }\end{array}$ & GPSS original & 2 \\
\hline Seminar on environmental politics and policy* & Department of International Studies & 2 \\
\hline Project on environment systems* & Department of environment systems & 2 \\
\hline Intensive practical course on sustainability & GPSS original; YES/IPoS & 1 \\
\hline \multicolumn{3}{|l|}{ Master's thesis research } \\
\hline Seminar course on sustainability science I-IV & Compulsory & 1 (total 4) \\
\hline Research on sustainability science & Compulsory & 6 \\
\hline
\end{tabular}

Participating students must take a minimum of eight units from the specified list of courses. The eight units must include courses marked with an asterisk $(*)$

As the GPSS is a part of the educational activities of the IR3S, the objective of it is to educate future leaders who can contribute to building a sustainable society according to the philosophy of sustainability science recognized by the IR3S. Higher education, which has the task of producing future leaders, should play an important role in creating a sustainable future (Cortese 2003).

\section{Development of the GPSS curriculum}

To meet the aforementioned objectives, the GPSS has developed the curriculum shown in Table 1. It consists of three parts: Knowledge and Concept Oriented Courses, Experiential Learning and Skills Oriented Practical Courses, and the Master's Thesis. The Knowledge and Concept 


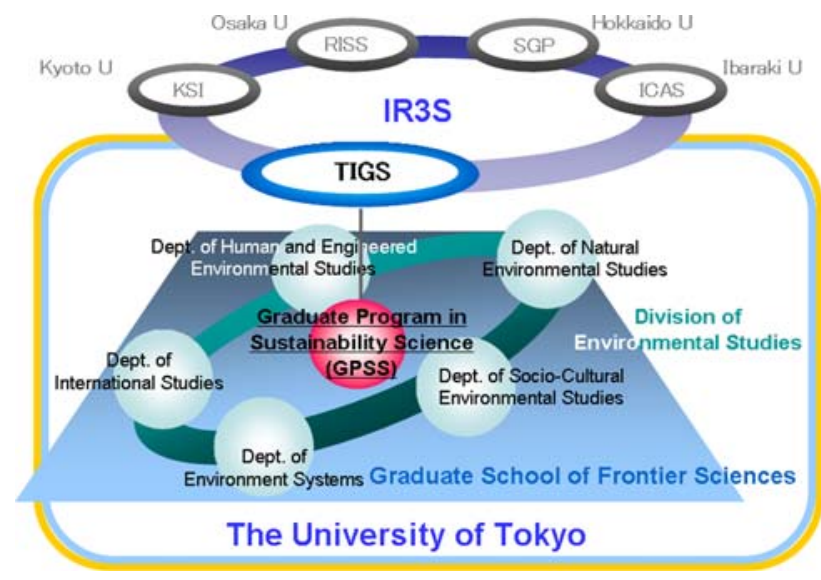

Fig. 1 Organization of the Graduate Program in Sustainability Science (GPSS)

Oriented Courses include core courses that deal with diverse sustainability-related subjects from a holistic viewpoint, and elective courses that deal with specific topics and can be taken according to the interests and needs of the individual student. The Experiential Learning and Skills Oriented Practical Courses include exercises intended to foster basic attitudes of acceptance of diversity and respect for minorities, as well as practical skills for action in the real world. This section describes how the GPSS has developed each part of this curriculum and the objectives of each part.

\section{Historical basis of the GPSS}

The GPSS was established as an interdepartmental master's program of the five departments in the Division of Environmental Studies, Graduate School of Frontier Sciences (GSFS) of the University of Tokyo. These are the Department of Natural Environmental Studies, Department of Environment Systems, Department of Human and Engineered Environmental Studies, Department of SocioCultural Environmental Studies, and the Department of International Studies. The Division of Environmental Studies was established in 1999 through university-wide transdisciplinary cooperation involving the entire University of Tokyo (Fig. 1). As an interdepartmental program, the GPSS is able to cover various research fields associated with the environment and sustainability.

Additionally, the Division of Environmental Studies has developed two unique diploma programs providing a core knowledge of environmental studies: the Environmental Management Program and the Integrated Environmental Design Program.

The Environmental Management Program began in 2004 and deals with practical aspects of environmental
Table 2 Course list of the Environmental Management Program

Sustainability perspectives in environmental issues
Fundamentals of environmental planning
Environmental business management
Environmental economics
Environmental systems
Natural environmental studies for sustainability
Introduction to socio-cultural and socio-physical environmental
studies
Business and finance for sustainable development

management. A list of courses offered in this program is shown in Table 2.

The Integrated Environmental Design Program began in 2006 and deals with different design aspects of the environment, including urban design, landscape design, rural design, natural environmental design, and human environmental design. It consists of studio workshops for small student groups.

These programs are offered by faculty members from various departments in the Division of Environmental Studies and attempt to apply transdisciplinary approaches to the curriculum design process.

\section{Knowledge and concept oriented courses}

Through the experiences of these previously established educational programs in the Division of Environmental Studies, the GPSS gained the capacity to deal with various sustainability-related issues in transdisciplinary and holistic ways, explore the boundary areas between traditional disciplines, and organize these components into a structured curriculum for the GPSS. The Knowledge and Concept Oriented Courses are an outcome of these efforts at the Division of Environmental Studies.

The Knowledge and Concept Oriented Courses include: (1) core courses that provide a holistic view of sustainability and cover relevant knowledge and disciplines associated with sustainability issues, and (2) a variety of elective courses selected from a wide range of academic fields, spanning the humanities and sciences, which have, heretofore, been part of the Division of Environmental Studies (Table 1).

\section{Core courses}

These courses consist of original courses designed for the GPSS through coordination with the Transdisciplinary Initiative for Global Sustainability (TIGS) and the IR3S, courses selected from the Environmental Management Program, and courses specifically offered to the GPSS by 
GPSS-supporting departments in the Division of Environmental Studies

"Sustainability Perspectives in Environmental Issues" and "Frontier of Sustainability Science" are designed to develop a holistic view of sustainability. "Sustainability Perspectives in Environmental Issues" is an outcome of serious consideration within the Division of Environmental Studies on how to structure sustainability issues in a holistic way. Though the process of structuring relevant knowledge associated with sustainability has not yet been completed, an institutional scheme for carrying out this task has already been established. Meetings of the GPSS Management Committee are held every two weeks and representatives of the concerned departments in the Division of Environmental Studies participate in these meetings to discuss how to manage and improve the GPSS curriculum.

"Frontier of Sustainability Science" was developed as a core course of the Joint Educational Program of the IR3S, a joint diploma program among the five IR3S partner universities. It is offered as a distance-learning course using TV conference systems and deals with up-to-date results from advanced studies of various sustainability issues conducted by the IR3S universities.

Major issues and disciplines related to sustainability are covered in the core courses. For example, climate change issues are addressed in "Strategies for Global Sustainability," resource management, environmental safety, and public health in "Environmental Sustainability," biodiversity and ecosystem conservation in "Natural Environmental Studies for Sustainability," water safety and security in "Urban Sustainability in Relation to the Water Sector," environmental business in "Business Administration for Environmental Technology" and "Business and Finance for Sustainable Development," environmental economics in "Environmental Economics," and innovation and technology in "Innovation and Sustainability" (Table 1).

Courses dealing with development issues ("Development Model") and sustainability education ("Sustainability Education") are offered as elective courses, while politics and governance are covered in one of the Experiential Learning and Skills Oriented Practical Courses, "Seminar on Environmental Politics and Policy." However, components dealing with sociology, ethics, human security, and poverty are still insufficient. The Management Committee of the GPSS continues to work on improving the structure of the core courses to offer a well-structured curriculum on sustainability.

Elective courses

Elective courses are selected from the entire Division of Environmental Studies curriculum to give students exposure to various academic fields related to sustainability according to their interests.

\section{Experimental short-term programs: YES and IPoS}

Other key experiences that have contributed to development of the GPSS curriculum are two short-term (about two weeks long) experimental programs on sustainability: Youth Encounter on Sustainability (YES, 2000-present), a collaborative program by the Massachusetts Institute of Technology (MIT), Swiss Federal Institute of Technology (ETH), Chalmers University, and the University of Tokyo; and the Intensive Program on Sustainability (IPoS, 2004present), a collaboration between the Asian Institute of Technology (AIT) and the University of Tokyo. Both programs accept students from all over the world and are designed to provide the students with exposure to a crosscultural and multidisciplinary environment and the opportunity to intensively discuss sustainability.

Through the YES and IPoS, we have learned that accepting diversity and respecting minorities in a diverse international society are extremely important aspects of sustainability education. This is also mentioned by Carter (2004). We have incorporated this perspective into the development of the Experiential Learning and Skills Oriented Practical Courses.

\section{Experiential learning and skills oriented practical courses}

The Experiential Learning and Skills Oriented Practical Courses are participatory in nature. Through exposure to diverse student groups and ideas in group discussions and dialogs, students become acquainted with a variety of perspectives among their fellow students and learn the importance of accepting diversity and respecting minorities. To ensure the participation of a broad diversity of students, the GPSS offers all lectures and courses in English so that language is not a constraint. We also provide scholarships and housing support so that foreign students may concentrate on their academic activities.

The Experiential Learning and Skills Oriented Practical Courses also emphasize practical exercises for acquiring various skills related to sustainability rather than simply gaining knowledge of the subject matter (Table 1). The coursework includes: training in the holistic thinking needed to appropriately assess sustainability-related issues from a holistic point of view; acquisition of the facilitation and negotiation skills necessary for building consensus; exercises to foster the understanding of cultural diversity that is essential to cross-cultural communication; and a 
wide range of case studies dealing with various examples of global, international, and regional problems. Students from many different disciplines and cultural backgrounds are expected to give serious thought to issues related to sustainability through demanding exercises and projects, and to acquire practical knowledge and skills by stimulating one another intellectually. The importance of transdisciplinary case studies is affirmed by Scholz et al. (2006).

\section{Master's thesis work}

A Master's Thesis is required by the GPSS. In their thesis work, students are encouraged to take a transdisciplinary approach to complex sustainability problems by integrating the diverse approaches, ways of thinking, and key principles of different disciplines. In some cases, professors from different departments may collaboratively supervise one student as a team. For those who wish to pursue a higher degree in relevant disciplines, the GPSS Master's Thesis work thus provides a unique experience.

\section{The degree: master of sustainability science}

The GPSS offers a master of sustainability science degree. Sustainability science is not an established discipline, and some may question whether a discipline that is not yet mature and has vaguely defined boundaries should even offer a degree. Sustainability science may not be a discipline that can be defined simply by the subjects it deals with, but it can be viewed as an academic field characterized by some core principles. These principles include holistic thinking, transdisciplinarity, and respect for diversity. If students are trained to understand these principles not only by gaining knowledge but also experience, it is the view of the GPSS that they should be entitled to a master of sustainability science degree.

\section{Future perspectives}

Though the focus of the GPSS is more on creating future leaders than on teaching sustainability science as an established subject, the conceptualization of sustainability science is still essential. The Management Committee of the GPSS will continue to meet the challenge of conceptualizing sustainability science and defining sustainability education, and will endeavor to keep improving the curriculum structure of the GPSS.

\section{References}

Carter L (2004) Thinking differently about cultural diversity: using postcolonial theory to (re)read science education. Sci Educ 88(6):819-836

Clark WC (2007) Sustainability science: a room of its own. Proc Natl Acad Sci USA 104:1737-1738

Cortese AD (2003) The critical role of higher education in creating a sustainable future. Plan High Edu 31(3):15-22

Graduate Program in Sustainability Science (GPSS) Home page at: http://www.sustainability.k.u-tokyo.ac.jp/

Graduate School of Frontier Sciences (GSFS) The University of Tokyo. Home page at: http://www.k.u-tokyo.ac.jp/index.html.en

Intensive Program on Sustainability (IPoS) Home page at: http://www. ipos.k.u-tokyo.ac.jp/

Integrated Research System for Sustainability Science (IR3S) Home page at: http://www.ir3s.u-tokyo.ac.jp/en/index.html

Kates RW, Clark WC, Corell R, Hall JM, Jaeger CC, Lowe I, McCarthy JJ, Schellnhuber HJ, Bolin B, Dickson NM, Faucheux S, Gallopin GC, Grübler A, Huntley B, Jäger J, Jodha NS, Kasperson RE, Mabogunje A, Matson P, Mooney H, Moore B 3rd, O'Riordan T, Svedin U (2001) Environment and development: sustainability science. Science 292:641-642

Komiyama H, Takeuchi K (2006) Sustainability science: building a new discipline. Sustain Sci 1:1-6

Scholz RW, Lang DJ, Wiek A, Walter AI, Stauffacher M (2006) Transdisciplinary case studies as a means of sustainability learning: historical framework and theory. Int J Sustain High Educ 7(3):226-251

Youth Encounter on Sustainability (YES) Home page at: http://www. sustainability.ethz.ch 